\title{
A possible association between medial depression of mandibular ramus and maximum bite force
}

\author{
M.Z. Adisen, A. Okkesim, M. Misirlioglu \\ Department of Oral and Maxillofacial Radiology, Faculty of Dentistry, Kirikkale University, Kirikkale, Turkey
}

[Received: 20 January 2018; Accepted: 28 February 2018]

Background: Medial depression of the mandibular ramus (MDMR) is an anatomical depression with unknown aetiology and described as a result of a slender mandibular ramus in the area of the mandibular notch. It is suggested that MDMR may be due to variations in muscle functions. The aim of this study is to compare the bite force of patients with and without MDMR detected on panoramic radiographs. Materials and methods: One hundred and ten patients (55 women and 55 men; mean age $22.69 \pm 2.85$ years) participated in this study. Patients were divided into two groups based on the presence of MDMR. Bite force of 55 patients with $M R M D$ and 55 patients without MDMR were determined using a bite force sensor. Non-parametric tests were used to assess differences between groups.

Results: Measurements showed statistically significant differences in bite force between genders $(p=0.00)$ with men having higher values $(535.98 \pm 187.85 \mathrm{~N})$ than women $(363.59 \pm 139.56 \mathrm{~N})$. The mean bite force in the sides with and without MDMR was $538.19 \pm 196.94 \mathrm{~N}$ and $396.22 \pm 157.69 \mathrm{~N}$, respectively. There was a statistically significant difference between groups with and without MDMR $(p=0.00)$. There was no statistically significant difference in bite force between groups according to Angle's classification ( $p=0.581$ ).

Conclusions: This study suggests that the presence of MDMR may be an indicator of high muscle activity. Patients with MDMR should be carefully examined for the risk of relapse prior to any surgical intervention. (Folia Morphol 2018; 77; 4: 711-716)

Key words: Angle's classification, bite force, medial depression of mandibular ramus, orthognathic surgery planning

\section{INTRODUCTION}

The medial depression of the mandibular ramus (MDMR) was first described in 1983 by Langlais et al. [11]. MDMR is a normal anatomical depression and described as a result of a slender mandibular ramus in the area of the mandibular notch [6]. On panoramic radiographs, these depression areas appear as a radiolucent region due to decreased absorption of $X$-rays. MDMR may be unilateral or bilateral and sometimes misinterpreted as a pathological condition $[6,11]$.
The aetiology of MDMR is still unclear. While some authors claim that it is a developmental variation, some others think that it is congenital [19]. MDMR area is thin, and an increased hassle in splitting the ramus may be anticipated. Patients with MDMR may therefore have an increased potential for complications such as bleeding, paresthesia and relapse [14, 17]. It is therefore useful to assess the presence of MDMR in patients who are to undergo orthodontic surgery. Using different investigation methods, studies 

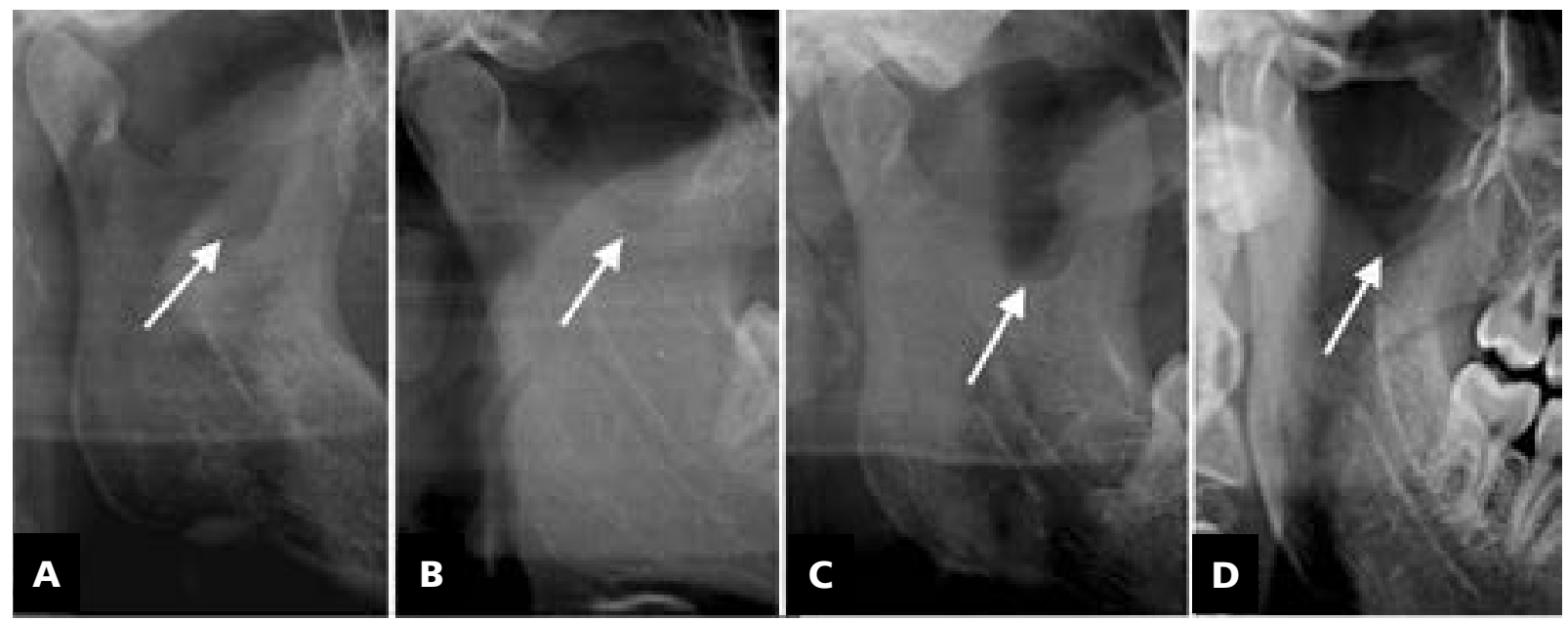

Figure 1. Different types of medial depression of the mandibular ramus on cropped panoramic radiographs; A. Tear-drop shape; B. Semilunar shape; C. Circular shape; D. Triangular shape.

report different prevalence rates of MDMR in different sample groups. Sudhakar et al. [19] report a higher prevalence of MDMR in patients with dentoskeletal deformities detected on panoramic radiographs.

Studies indicate that the medial and posterior attachments of temporal muscle are held into sigmoid area, and therefore, the size and shape of MDMR may be due to variations in muscle function [18]. It is reasonable to draw an association between the size and function of the masticatory muscles and craniofacial morphology [15]. Accordingly, the function of the temporal and masseter muscles shows correlation with bite force [15, 24].

Though the effect of bite force on the aetiology of MDMR is unknown, some researchers argue that muscle function may be associated with MDMR since the medial and posterior attachments of temporal muscle are inserted in this area. However, no studies have been conducted so far to investigate this possible association. The aim of this study is to investigate the effect of bite force on the aetiology of MDMR on the assumption that MDMR could be an indicator of masticatory muscle function in orthognathic patients before any surgical intervention. Moreover, information on muscle activity can be used to determine post-operative relapse risks and further treatment options.

\section{MATERIALS AND METHODS}

A power analysis was performed using $\mathrm{G}^{*}$ power, version 3.1.9.2 (Franz Faul, Universität Kiel, Germany). Results showed that a total sample size of 102 patients would give more than $80 \%$ power (actual power $=$ 0.8058 ) to detect significant differences with an effect size of 0.50 at a significance level alpha $=0.05$. To this end, 110 patients between the ages of 18 and 30 years ( 55 women and 55 men; mean age $22.69 \pm 2.85$ years) were recruited for the study. Affecting the measurement of bite force, anthropometric evaluation was performed. Body mass index (BMI) was calculated in kilograms per square meter and patients within the normal range of BMI (18.50-24.99) were included in the study [25].

Patients were divided into two groups based on the presence of MDMR on panoramic radiographs. Group 1 and Group 2 (control group) consisted of patients with and without MDMR, respectively. All volunteers read and signed an informed consent form prior to participation in the study. The study was approved by the administration of the Faculty of Dentistry and conducted in accordance with the guidelines of the Helsinki Declaration, with no invasive procedure performed.

Patients excluded from the study are those with 1) developmental malformations and pathologies in the maxillofacial region, 2) a history of trauma in the maxillofacial region, 3) muscular disorders, 4) bruxism, 5) a unilateral chewing habit, 6) temporomandibular disorders, 7) no maxillary/mandibular permanent first molars and 8) a history of surgical intervention in the mandibular ramus area.

All participants were selected from patients undergoing routine radiographic examination. Panoramic radiographs were taken using a digital panoramic radiography unit (Instrumentarium OP200D; Tuusula, Finland). MDMRs were detected and classified by two oral radiologists. Geometric shapes of MDMR were classified based on the varieties available in the literature: tear-drop, semilunar, circular and triangular (Fig. 1) $[6,11]$. The control group was randomly selected. 

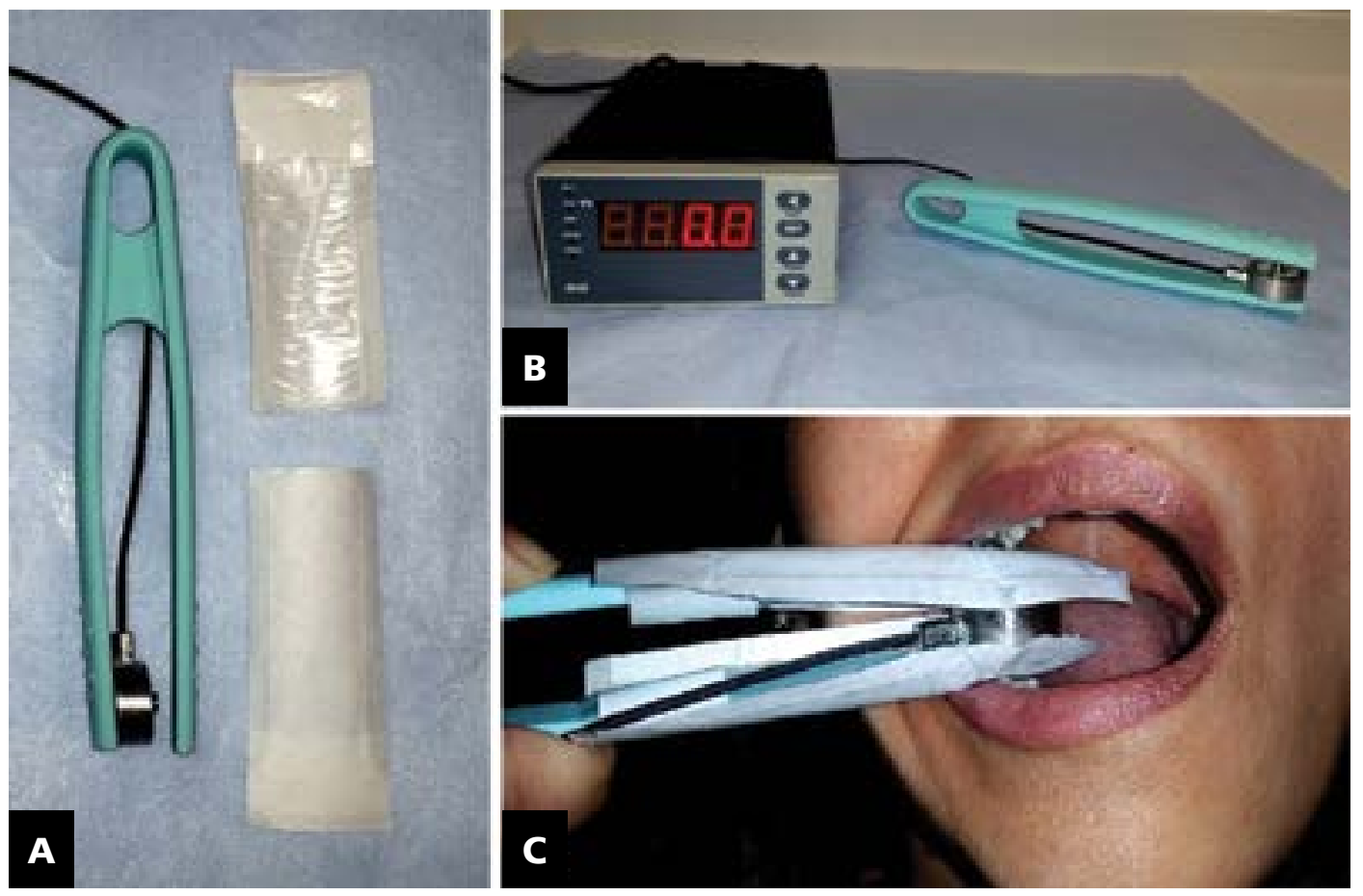

Figure 2. Bite force sensor device is manufactured for medical purposes and suitable for oral using; $\mathbf{A}$. The force sensor is made of stainless steel plates and the external surface is covered with rubber to make it easy to bite. Disposable plastic covers were used for every patient; B. The digital indicator of the device shows kilograms. All the measured values were then converted to newtons (N); C. Bite force measurements were made between maxillary and mandibular first molars on the right and left side.

Bite force of participants was measured using a bite force sensor (Viste, Hong Kong, China) manufactured for medical purposes. The force sensor is made of stainless steel plates. The external surface is covered with rubber that provides easy bite for patients (Fig. 2A). The device displays values in kilograms converted into Newton (N) force values (Fig. 2B).

Bite force measurements were made between maxillary and mandibular first molar teeth on the right and left side (Fig. 2C). Prior to measurements, the patient was told to sit on the examination chair and his/her head was positioned with the Frankfurt Horizontal Plane parallel to the floor. He/she was instructed to bite the sensor with maximum force without moving his/her head. Once bite force reached maximum on the digital indicator, the procedure was terminated. Bite force was measured twice from the right and left side, and the mean value of each measurement was registered. Data were analysed using the Statistical Package for Social Sciences (SPSS), version 20. Normality of data distribution was tested using Kolmogorov-Smirnov and Shapiro-Wilk tests. Since the data were not normally distributed $(p<0.05)$, Kruskal-Wallis and Mann-Whitney $U$ tests were used for statistical comparisons between the groups.

\section{RESULTS}

There was a statistically significant difference in bite force between the genders $(p=0.00)$, with men having higher values $(535.98 \pm 187.85 \mathrm{~N})$ than women $(363.59 \pm 139.56 \mathrm{~N})$. The mean bite force in the sides with and without MDMR was $538.19 \pm$ $\pm 196.94 \mathrm{~N}$ and $396.22 \pm 157.69 \mathrm{~N}$, respectively. There was a statistically significant difference in bite force between groups with and without MDMR $(p=0.00)$.

There was no statistically significant difference in bite force between different occlusion types ( $p=0.581$ ). Patients with Angle's class I occlusion (460.41 N) had a higher bite force than Angle's class II $(447.19 \mathrm{~N})$ and Angle's class III (441.02 N) groups. Table 1 shows the mean values of measurements.

Regarding the shape of MDMRs, semilunar (36\%) was the most common, followed by circular (29\%), triangular (23\%), and teardrop (12\%). There was no statistically significant $(p=0.486)$ difference in bite force between MDMR types. Semilunar and circular shapes had higher values than other types of MDMR (Table 2).

According to Angle's classification, the prevalence of MDMR was highest in class I (52.5\%), followed by class III (48.7\%) and class II (48.4\%). 
Table 1. Comparison of maximum bite force between groups

\begin{tabular}{lcccc}
\hline & Number & Mean (Newton) & SD & P \\
\hline Gender & & & & \\
Female & 55 & 363.59 & 139.56 & $0.000^{*}$ \\
Male & 55 & 535.98 & 187.85 & \\
Medial depression & & & & \\
With & 83 & 538.19 & 196.94 & $0.000^{*}$ \\
Without $_{\text {Angle's classification }}^{\# \#}$ & 137 & 396.22 & 157.69 & \\
Class I & 40 & 460.41 & 204.19 & \\
Class II & 31 & 447.19 & 159.93 & 0.581 \\
Class III & 39 & 441.02 & 188.11 & \\
\hline
\end{tabular}

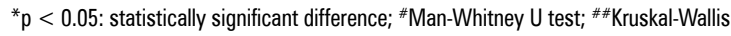
test; SD — standard deviation

Table 2. Comparison of maximum bite force between different medial depression types

\begin{tabular}{lcccc}
\hline & Number & Mean (Newton) & SD & P \\
\hline Tear-drop & 10 & 519.00 & 111.08 & \\
Semilunar & 30 & 532.23 & 186.09 & \\
Circular & 24 & 591.37 & 235.37 & 0.486 (NS) \\
Triangular & 19 & 490.52 & 193.65 & \\
\hline
\end{tabular}

NS - p > 0.05: statistically not significant difference; Kruskal-Wallis test; SD — standard deviation

Table 3. Distribution of patients with/without medial depression according to Angle's classification

\begin{tabular}{lcccc}
\hline \multirow{2}{*}{$\begin{array}{l}\text { Angle's } \\
\text { classification }\end{array}$} & \multicolumn{2}{c}{ Medial depression } & Total & P \\
\cline { 2 - 3 } & With & Without & & \\
\hline Class I & $21(52.5 \%)$ & $19(47.5 \%)$ & 40 & \\
Class II & $15(48.4 \%)$ & $16(51.6 \%)$ & 31 & 0.53 (NS) \\
Class III & $19(48.7 \%)$ & $20(51.3 \%)$ & 39 & \\
\hline
\end{tabular}

NS $-p>0.05$ : statistically not significant difference; Chi-square test

There was, however, no statistically significant difference in prevalence between the groups $(p=0.53$; Table 3).

\section{DISCUSSION}

The jaw muscles are regularly used. Their adaptive changes are not always consistent but vary according to the features of teeth, and force and duration of stimulus. The jaw muscles apply forces on the teeth and jaw in order to monitor the position and movement of the mandible. The jaw muscles can evoke strong contractions due to the regular system of their contractile fibres [8]. A large spectrum of stimuli affecting the jaw muscles may reveal information on anatomical and physiological variations in individuals. Kitai et al. [9] used computed tomography to analyse craniofacial structures and reported that local skeletal sites were affected by adjacent elevator muscles with mechanical stresses. Moreover, Storey [18] claimed that the size and shape of depression in bone may be due to variations in muscle function. In light of this information, we assumed that there might be an association between muscle function and MDMR. In order to analyse this phenomenon, we compared bite force of patients with and without MDMR to see if there is any statistically significant difference between them.

Comparing bite force performance was the method of choice because bite force is the only indicator of muscle activity that can be measured via oral cavity using a simple device. Besides, there is a close positive relationship between the electromyographic activity of the jaw elevator muscles and bite force (the masseter, temporal and medial pterygoid muscles) during isometric contractions [15, 24].

Using a similar method, Szymańska and Sidorowicz $[16,21]$ evaluated the relationship between bite force and facial skeleton morphology. They found a significant relationship between bite force and the posterior height of the maxilla alveolar process.

The present results show that there is a statistically significant difference in bite force between patients with and without MDMR ( $p=0.00)$. Considering the impact of muscle activity on bone development, we can state that these results are reasonable. We can therefore argue that muscle activity may be involved in the etiology of MDMR and that patients with MDMR may have better bite force performance than those without MDMR.

Maximum bite force is one of the most important indicators of the functional situation of the masticatory system and its value is used to diagnose disorders of the musculoskeletal system of facial skeleton [20]. Maximum bite force is affected by skeletal craniofacial morphology, depending on the posterior/ anterior facial height ratio, vertical facial relationships, mandibular inclination and gonial angle [16, $21,22]$. Malocclusions are commonly associated with reduced maximum bite force. Therefore, orthodontic treatment may be necessary to increase function [23]. There are many studies that investigate how maximum bite force affects the development of cran- 
iofacial morphology and dental malocclusions [1, 3]. Bite force occurs as a result of the upward movement of the mandible like a leverage. The more vertical the ramus and sharper the gonial angle, the greater mechanical advantage the elevator muscles have $[1,5]$. MDMR is also reported to be associated with different skeletal traits. Dalili and Mohtavipour [7] reported a higher prevalence of MDMR in patients with malocclusion while Sudhakar et al. [19] reported a higher prevalence of MDMR in Angle's class II malocclusions (9.3\%) than in Angle's class III (7.6\%). Some studies also report that MDMR is more prevalent in patients with dentoskeletal deformities than in patients with an Angle's class I occlusion [4]. However, on the contrary, the results of this study show that patients with an Angle's class I occlusion have a higher prevalence of MDMR even though the difference in prevalence between the groups is not statistically significant. This result may be due to the small sample size. Another important result of this study is that Angle's class I occlusion group (460.41 N) had higher bite force values than Angle's class II $(447.19 \mathrm{~N})$ and Angle's class III (441.02 N) groups. However, there is no statistically significant difference between the groups, which may due to the fact that the dental classification of malocclusion does not reflect the skeletal malformation of patients.

Maximum bite force is highest in the molar region. Maximum bite force in the molar region ranges from $300 \mathrm{~N}$ to $600 \mathrm{~N}$ in healthy adults with natural teeth [2]. Maximum bite force is usually reported to be higher in men than in women, which is also confirmed by this study. The greater muscular potential of men may be associated with anatomical differences [12]. Previous studies suggest that hormonal differences between men and women may have an effect on the composition of muscles [13]. However, differences in maximum bite force between men and women are not evident until the age of 18 years. It is obvious that maximum bite force increases during growth and development without gender specificity. During the post-pubertal period, maximum bite force increases at a higher ratio in men than in women depending on hormonal activity, and therefore, it becomes gender-specific $[3,10]$.

\section{CONCLUSIONS}

Results show that muscle activity may be involved in the aetiology of MDMR and that the presence of MDMR may be an indicator of high muscle activity, which is important especially in orthognathic surgery planning. Since high muscle activity is considered to be a risk for relapse, patients with MDMR should be carefully evaluated prior to any surgical intervention.

\section{REFERENCES}

1. Bakke M. Bite force and occlusion. Semin Orthod. 2006; 12(2): 120-126, doi: 10.1053/j.sodo.2006.01.005.

2. Bakke $M$, Michler L, Han $K$, et al. Clinical significance of isometric bite force versus electrical activity in temporal and masseter muscles. Scand J Dent Res. 1989; 97(6): 539-551, doi: 10.1111/j.1600-0722.1989.tb00929.x, indexed in Pubmed: 2617156.

3. Braun S, Bantleon HP, Hnat WP, et al. A study of bite force, part 1: Relationship to various physical characteristics. Angle Orthod. 1995; 65(5): 367-372, doi: 10.1043/0003-3219(1995)065<0367:ASOBFP $>2.0$. CO;2, indexed in Pubmed: 8526296.

4. Carvalho IM, Damante JH, Tallents RH, et al. An anatomical and radiographic study of medial depression of the human mandibular ramus. Dentomaxillofac Radiol. 2001; 30(4): 209-213, doi: 10.1038/sj.dmfr.4600609, indexed in Pubmed: 11681482.

5. Castelo PM, Bonjardim LR, Pereira $\amalg$, et al. Facial dimensions, bite force and masticatory muscle thickness in preschool children with functional posterior crossbite. Braz Oral Res. 2008; 22(1): 48-54, doi: 10.1590/S180683242008000100009 , indexed in Pubmed: 18425245.

6. Clark M, McAnear J. Pseudocyst in the coronoid process of the mandible. Oral Surg Oral Med Oral Pathol Oral Radiol Endod. 1984; 57(2): 231, doi: 10.1016/0030-4220(84)90219-6.

7. Dalili Z, Mohtavipour S. Frequency of medial sigmoid depression in panoramic view of orthodontic patients based on facial skeletal classification. J Guilan University Med Scien. 2003; 12(45): 16-23.

8. Grünheid T, Langenbach GEJ, Korfage JAM, et al. The adaptive response of jaw muscles to varying functional demands. Eur J Orthod. 2009; 31(6): 596-612, doi: 10.1093/ ejo/cjp093, indexed in Pubmed: 19656804.

9. Kitai N, Fujii Y, Murakami S, et al. Human masticatory muscle volume and zygomatico-mandibular form in adults with mandibular prognathism. J Dent Res. 2002; 81(11): 752-756, doi: 10.1177/0810752, indexed in Pubmed: 12407089.

10. Koc D, Dogan A, Bek B. Bite force and influential factors on bite force measurements: a literature review. Eur J Dent. 2010; 4(2): 223-232, indexed in Pubmed: 20396457.

11. Langlais RP, Glass BJ, Bricker SL, et al. Medial sigmoid depression: a panoramic pseudoforamen in the upper ramus. Oral Surg Oral Med Oral Pathol Oral Radiol Endod. 1983; 55(6): 635-638, doi: 10.1016/0030-4220(83)90385-7, indexed in Pubmed: 6576296.

12. Olthoff LW, van der Glas HW, van der Bilt A. Influence of occlusal vertical dimension on the masticatory performance during chewing with maxillary splints. J Oral Rehabil. 2007; 34(8): 560-565, doi: 10.1111/j.1365-2842.2007.01730.x, indexed in Pubmed: 17650165.

13. Pizolato RA, Gavião MB, Berretin-Felix G, et al. Maximal bite force in young adults with temporomandibular disorders and bruxism. Braz Oral Res. 2007; 21(3): 278-283, doi: 10.1590/ S1806-83242007000300015, indexed in Pubmed: 17710296.

14. Quinn PD, Wedell D. Complications from intraoral vertical subsigmoid osteotomy: review of literature and report of 
two cases. Int J Adult Orthodon Orthognath Surg. 1988; 3(4): 189-196, indexed in Pubmed: 3075977.

15. Raadsheer MC, van Eijden TM, van Ginkel FC, et al. Contribution of jaw muscle size and craniofacial morphology to human bite force magnitude. J Dent Res. 1999; 78(1): 31-42, doi: 10.1177/00220345990780010301, indexed in Pubmed: 10065943.

16. Sidorowicz $Ł$, Szymańska J. The relationship between facial skeleton morphology and bite force in people with a normal relation of the bases of jaws and skull. Folia Morphol. 2015; 74(4): 508-512, doi: 10.5603/FM.2015.0115, indexed in Pubmed: 26620514.

17. Smith BR, Rajchel JL, Waite DE, et al. Mandibular ramus anatomy as it relates to the medial osteotomy of the sagittal split ramus osteotomy. J Oral Maxillofac Surg. 1991; 49(2): 112-116, doi: 10.1016/0278-2391(91)90095-4, indexed in Pubmed: 1990086.

18. Storey E. Growth and remodeling of bone and bones. Role of genetics and function. Dent Clin North Am. 1975; 19(3): 443-455, indexed in Pubmed: 1055699.

19. Sudhakar S, Kumar N, Prabhat M, et al. Characteristics of medial depression of the mandibular ramus in patients with orthodontic treatment needs: a panoramic radiography study. J Clin Diagn Res. 2014; 8(11): ZC100-ZC104, doi: 10.7860/ JCDR/2014/9869.5192, indexed in Pubmed: 25584298.

20. Szymańska J, Sidorowicz $Ł$. Bite force and its correlation with long face in children and youth. Folia Morphol. 2015;
74(4): 513-517, doi: 10.5603/FM.2015.0116, indexed in Pubmed: 26620515.

21. Szymańska J, Sidorowicz $Ł$. The relationship between selected parameters of a cephalometric analysis determining the vertical morphology of facial skeleton and bite force. Folia Morphol. 2017; 76(4): 736-741, doi: 10.5603/fm.a2017.0040, indexed in Pubmed: 28553859.

22. Throckmorton GS, Ellis E, Buschang PH. Morphologic and biomechanical correlates with maximum bite forces in orthognathic surgery patients. J Oral Maxillofac Surg. 2000; 58(5): 515-524, doi: 10.1016/\$0278-2391(00)90014-4, indexed in Pubmed: 10800907.

23. Tsai $\mathrm{HH}$. Maximum bite force and related dental status in children with deciduous dentition. J Clin Pediatr Dent. 2004; 28(2): 139-142, doi: 10.17796/jcpd.28.2. j42870t47q4n1715, indexed in Pubmed: 14969373.

24. Van Spronsen P, Weijs WA, Valk J, et al. Relationships between jaw muscle cross-sections and craniofacial morphology in normal adults, studied with magnetic resonance imaging. Eur J Orthod. 1991; 13(5): 351-361, doi: 10.1093/ejo/13.5.351, indexed in Pubmed: 1748181.

25. WHO Expert Consultation. Appropriate body-mass index for Asian populations and its implications for policy and intervention strategies. Lancet. 2004; 363(9403): 157-163, doi: 10.1016/S0140-6736(03)15268-3, indexed in Pubmed: 14726171. 